\title{
CDISC SDTM Reference Range Indicator
}

National Cancer Institute

\section{Source}

National Cancer Institute. CDISC SDTM Reference Range Indicator. NCI Thesaurus. Code C78736.

Terminology associated with the reference range indicator codelist of the Clinical Data Interchange Standards Consortium (CDISC) Study Data Tabulation Model (SDT M). 